Purdue University Purdue e-Pubs

$1-1-1994$

\title{
Economic Exposure and Integrated Risk Management
}

Kent D. Miller

Purdue University

Follow this and additional works at: http://docs.lib.purdue.edu/ciberwp

Miller, Kent D., "Economic Exposure and Integrated Risk Management" (1994). Purdue CIBER Working Papers. Paper 81. http://docs.lib.purdue.edu/ciberwp/81

This document has been made available through Purdue e-Pubs, a service of the Purdue University Libraries. Please contact epubs@purdue.edu for additional information. 


\title{
ECONOMIC EXPOSURE AND INTEGRATED RISK MANAGEMENT
}

\author{
Kent D. Miller \\ Purdue University
}

94-004
Center for International Business Education and Research Purdue University Krannert Graduate School of Management 1310 Krannert Building West Lafayette, IN 47907-1310
Phone: (317) 494-4463
FAX: (317) 494-9658




\title{
ECONOMIC EXPOSURE AND INTEGRATED RISK MANAGEMENT
}

\author{
KENT D. MILLER \\ Krannert Graduate School of Management \\ Purdue University \\ 1310 Krannert Building \\ West Lafayette, IN 47907-1310 \\ (317) 494-5903 \\ BITNET: kmiller@purccvm.bitnet
}

November 29, 1993

First Draft. The author welcomes your comments. 


\section{ECONOMIC EXPOSURE AND INTEGRATED RISK MANAGEMENT}

Most corporate risk management research focuses on particular risk exposures to the exclusion of other interrelated exposures. By contrast, this study models corporate risk exposures using a multivariate approach integrating the distinct exposures of interest to finance and strategy researchers. The paper addresses the implications of multivariate modeling for corporate risk management, some key methodological issues arising in empirical estimation of corporate economic exposures, and directions for research on integrated risk management.

Funding from Krannert's Center for International Business Education and Research is gratefully acknowledged. 
Exposure refers to the extent to which external environmental contingencies have an impact on a company's performance. In the past, scholarly interest in corporate risk exposure has come almost exclusively from the accounting and finance fields. Interest in corporate foreign exchange exposure arose from the practical need to consolidate the financial statements of foreign operations to local currencies (translation exposure) and the possibility of incurring accounting gains or losses on receivables and payables denominated in foreign currencies (transaction exposure). While much attention has been given to foreign exchange exposure, finance researchers have also considered exposures to movements in other financial market variables, such as interest rates and commodity prices.

Economic exposure considers the sensitivity of the real value of a company to fluctuations in environmental contingencies. The focus on economic valuation contrasts with accounting exposure defined in terms of the book values of assets and liabilities denominated in foreign currencies. While accounting exposure is a function of nominal movements in foreign exchange rates, economic exposure focuses on real changes in foreign exchange rates. Real, rather than nominal exchange rate movements, have an impact on the competitive position of a company, affecting cash flows and market valuation of the firm. As such, economic exposure considers future cash flows rather than historical accounting values.

While scholars have acknowledged economic exposure as the theoretically relevant concept for corporate risk assessment, corporate risk management practices for the most part continue to reflect accounting-based notions of exposure assessment (Batten, Mellor, \& Wan, 1993; Rawls \& Smithson, 1990). Although there appears to be growing interest in economic exposure among managers, only a few large multinationals have implemented economic exposure assessment and management using financial market instruments (Kohn, 1990; Lewent \& Kearney, 1990). Lessard contends current foreign exchange management thinking and practice is flawed in two respects:

First, foreign exchange risk management is concerned primarily with deciding whether to hedge or retain particular exposures arising from operations rather than seeing to it that this exposure and its impact on expected operating profits have been factored into operating decisions. In fact, as practiced, it differs little from staking the assistant treasurer with a sum of money to be used to speculate on stock options, pork bellies, or gold. Second, it tends to focus on exposures that lead to identifiable foreign exchange gains or losses, contractual items as opposed to operating profit impacts (1986: 166). 
Two factors may account for these shortcomings in corporate risk management practices. First, management reliance on financial hedging instruments may be due to the lack of clear guidance regarding the role of strategic decisions in corporate risk management. A stark contrast exists between the precision of finance research on hedging and the vague discussions of strategic risk management. While finance researchers have contributed to the development of sophisticated hedging instruments for managing specific corporate risks (e.g., foreign exchange and interest rate options, and commodity futures and forward contracts), strategy researchers offer little specific guidance to managers concerned about exposures to specific environmental uncertainties. Frequently, strategy research offers little guidance beyond the general platitude that firms operating in uncertain environments ought to adopt changes resulting in increased strategic flexibility. That exposures to different uncertain environmental contingencies require different strategic responses has not received adequate attention.

Second, the lack of clear guidelines for measuring economic exposure is a major obstacle to implementing economic exposure assessment and hedging programs. While Dufey (1972) drew attention to the need to rethink foreign exchange exposure in economic rather than accounting terms, finance research has not adequately addressed the practical issue of how to measure corporate economic exposure.

This study seeks to respond to these two deficiencies. The primary focus is on the measurement of corporate economic exposure. In developing a conceptual and operational basis for measuring economic exposure, the study also lays the groundwork for strategy research directed at understanding the role of corporate strategy in economic exposure management.

The next section develops a multivariate model of corporate economic exposure. The starting point for this model is corporate foreign exchange exposure but, as discussed, the model can also be extended to an integrated framework incorporating other environmental contingencies. This is followed by a discussion of the implications of multivariate assessment of economic exposure. The multivariate approach has implications for both corporate risk assessment and management. Next, the paper seeks to resolve some key methodological issues that must be addressed in order to actually measure corporate economic exposures. The final section discusses directions for extending this research. 


\section{MULTIVARIATE EXPOSURE}

Most corporate risk management research to date reflects a "particularist" view. That is, researchers focus on particular risk exposures to the exclusion of other interrelated exposures. Finance researchers have focused on the exposures for which there are well-developed markets and hedging instruments such as foreign exchange, interest rate, and commodity prices. International business scholars have given extensive attention to political risk. In the strategy field, researchers have focused on competitive, input supply, market demand, and technological risk exposures. Given the focus on particular risk exposures, there has been little conceptual and modeling work integrating the various categories of corporate risk exposures. Most research on economic exposure considers simple bivariate relations between firm value (or cash flows) and a single environmental variable, most frequently a foreign exchange rate. There is still a need for a well-developed multivariate model of economic exposures which explicitly takes into account the interrelations among various exposures. This section seeks to fill that need.

\section{Economic Exposure to Multiple Foreign Exchange Rates}

Adler and Dumas (1984) and Garner and Shapiro (1984) proposed simple bivariate linear models of exchange exposure. Following their work, we would express the exposure of a dollar-priced asset to movements in the dollar-pound exchange rate as:

$$
V(t)=\beta_{0}+\beta_{1} S_{\mathfrak{E}}(t)+\varepsilon(t)
$$

where $S_{\mathfrak{E}}(t)$ denotes the real spot dollar price of one pound at time $t, V(t)$ is the real dollar value of the firm, and $\varepsilon(t)$ is the random error term. As specified, the U.S. dollar is assurned to be the relevant functional currency for valuing the firm. We further assume the error term is normally distributed with mean zero and a constant variance, i.e., $\varepsilon(t) \sim N\left(0, \sigma^{2}\right)$. In this simple bivariate model, the coefficient reflecting the exchange rate exposure, $\beta_{1}$, equals $\rho_{V S}=\operatorname{cov}\left[V_{\$}(t), S_{\mathfrak{E}}(t)\right] / v a r\left[S_{\mathfrak{E}}(t)\right]$. The OLS estimate for the parameter $\beta_{1}$ is simply $b_{1}=r_{V \mathfrak{f}}$, the sample correlation between $V(t)$ and $S_{\mathfrak{E}}(t)$.

For an estimated exposure coefficient $b_{1}>0$, full hedging involves selling $b_{1}$ pounds for dollars. If $b_{1}<0$, a hedging strategy of purchasing $b_{1}$ pounds with dollars would eliminate the exposure. If $b_{1}=$ 
0 , there is no exposure to movements in the dollar-pound exchange rate. The best estimate of the residual variance associated with the fully hedged position is $s^{2}$, the estimator of $\sigma^{2}$, equal to the mean of the squared residuals.

While Garner and Shapiro (1984) note that the bivariate model (1) can be extended to multivariate models allowing for asset exposures to multiple currencies, they do not consider the implications of switching from bivariate to multivariate exposure measures. Although simplification to the bivariate case is useful for illustrative purposes, focusing on bivariate relations can greatly distort estimated currency exposures. Bivariate estimates of exposure coefficients overlook the interrelations among exposures. Consider the following model expressing economic exposure in terms of two currencies:

$$
V(t)=\beta_{0}+\beta_{1} S_{£}(t)+\beta_{2} S_{\Psi}(t)+\varepsilon(t), \varepsilon(t) \sim N\left(0, \sigma^{2}\right) .
$$

$S_{¥}(t)$ denotes the real spot dollar price of one yen at time $t$ and the other variables are defined as before. In this case the exposure to movements in the dollar price of the pound sterling, $\beta_{1}$, is the partial derivative with respect to $S_{£}(t)$ which is conditional on $S_{\Psi}(t)$. Similarly, the yen exposure coefficient, $\beta_{2}$, is conditional on the pound spot price.

The conditional nature of multivariate model regression coefficients can be illustrated using the path model corresponding to equation (2) shown in figure $1 .^{1}$ In figure $1, \rho_{\mathfrak{f}}$ is the correlation between the real spot dollar prices of the pound and the yen. The model is just identified. While the true values of the model parameters are unknown, they can be estimated using sample correlations. Following the paths in the diagram (see Kenny, 1979), we can express the two sample correlations between real spot currency prices and real firm value as:

$$
r_{V f}=b_{1}+b_{2} r_{f ¥}
$$

$$
r_{V ¥}=b_{2}+b_{1} r_{f \Psi} \text {. }
$$

where $r_{\mathfrak{}}$ is the sample estimate of $\rho_{\mathfrak{}}$ and $b_{1}$ and $b_{2}$ are the estimates of $\beta_{1}$ and $\beta_{2}$, respectively.

Solving for the two parameters estimates in terms of the sample correlations, we have the OLS estimates:

$$
\begin{aligned}
& b_{1}=\left(r_{V \mathfrak{E}}-r_{V} \Psi_{\mathfrak{f}}\right) /\left(1-r_{\mathfrak{f} \Psi}{ }^{2}\right) \\
& b_{2}=\left(r_{V ¥}-r_{V ¥} T_{£}\right) /\left(1-r_{£}{ }^{2}\right) \text {. }
\end{aligned}
$$


Each regression coefficient is a function of the correlation between the predictor variables, $\mathbf{r}_{\mathfrak{f} \neq}$, as well as the correlations of a predictor with the endogenous variable. Hence, for any nonzero correlation between the spot prices of the yen and the pound, estimated multivariate exposure coefficients will differ from the coefficients derived by running two separate bivariate OLS regressions. For exposure regression models with more than two explanatory variables, the parameter estimates can also be expressed in terms of the correlations between the predictor variables, and predictor-dependent variable correlations. The expressions are, however, more complex than (5) and (6).

If the true model is equation (2), estimating two bivariate models similar to equation (1) can greatly distort the estimated exposure coefficients. While the estimated pound exposure coefficient from the bivariate equation (1) may be significant, the estimated pound coefficient in the multivariate equation (2) may not be significant. Altematively, an insignificant relation in equation (1) may be highly significant in the multivariate equation (2). Furthermore, the signs of significant parameters may reverse themselves when moving from bivariate to multivariate modeling of exposure coefficients. In short, all of the problems associated with specification error due to omitted variables apply to the misspecification of economic exposure models as simple bivariate relations (see Kenny, 1979: 62-65).

If the pound and yen spot prices have a nonzero correlation, the bivariate coefficients will indicate different quantities of pounds and yen to be bought or sold in order to fully hedge the foreign exchange exposures. Furthermore, if the sign of the bivariate exposure coefficient is reversed from that in the multivariate model, hedging based on the bivariate exposure estimate will increase, rather than reduce, the exposure.

\section{Exchange Rate Exposure in an Integrated Risk Management Framework}

The previous section contrasted bivariate and multivariate models of foreign exchange risk exposure. Taking the multivariate conceptualization of exposures one step further, it is important to recognize that in addition to exposures to multiple foreign currencies, companies have exposures to a variety of other uncertain environmental contingencies. Oxelheim and Wihlborg point out, "...managing exchange rate exposure per se is not clearly meaningful without considering the interdependence between 
the exchange rate and other variables related to the exchange rate in a general equilibrium system such as inflation rates and interest rates" (1987a: 88). Consistent with this reasoning, Grammatikos, Saunders, and Swary (1986) considered the joint implications of exchange rate and interest rate risks for U.S. banks. Kawai and Zilcha (1986) modeled export firm behavior under foreign currency and commodity price uncertainties.

While finance researchers have broadened the concept of corporate exchange risk management to include interrelated macroeconomic variables, they neglect the interrelated risk exposures of most interest to corporate strategists. Competitive, input supply, and product demand risks are often interrelated with movements in real exchange rates. Since industry variables affecting the competitive position of a firm may be interrelated with movements in exchange rates, the effect of exchange rates may be negligible after partialling out such variables. By focusing on exchange rate and other macroeconomic exposures, previous finance research may have overlooked the most relevant economic exposures such as exposures to strategic moves by competing firms.

For example, if Japanese exporters to the U.S. reduce real dollar prices in response to yen devaluations, this increases the economic exposure of competing U.S. firms to movements in the real value of the yen. If Japanese exporters' response is symmetric (i.e., they raise real dollar prices in response to yen appreciation), the magnitude of the economic exposure of U.S. firms is further increased. On the other hand, if Japanese exporters maintain constant dollar prices in the face of yen appreciation or depreciation, the yen exposure of U.S. competitors is reduced. Hence, the strategic variable of product pricing by Japanese competitors affects the foreign exchange exposure of U.S. firms, even U.S. firms producing and selling exclusively in their home market.

Expanding on the model developed earlier, we could incorporate the real dollar price of competing Japanese products, $P(t)$, into the economic exposure model.

$$
V(t)=\beta_{0}+\beta_{1} S_{£}(t)+\beta_{2} S_{\Psi}(t)+\beta_{3} P(t)+\varepsilon(t), \varepsilon(t) \sim N\left(0, \sigma^{2}\right)
$$

If as the yen decreases in real value, Japanese exporters seek to increase their U.S. market shares through reductions in their real dollar price, $\mathrm{P}(\mathrm{t})$ would be positively correlated with $\mathrm{S}_{\mathbf{Z}}(\mathrm{t})$. Hence, the estimated 
yen exposure coefficient, $\beta_{2}$, in equation (7), may be quite different from that estimated using equation (2).

As noted earlier, the price of foreign competitors' exports is just one of many variables that may be interrelated with movements in foreign exchange rates. We could also incorporate other variables that have an impact on firm value such as the prices for inputs, substitutes, and domestic competitors' goods. A general model for economic exposures would take the form:

$$
\mathrm{V}(\mathrm{t})=\mathrm{X}(\mathrm{t}) \beta+\varepsilon(\mathrm{t}), \varepsilon(\mathrm{t}) \sim N\left(0, \sigma^{2}\right)
$$

where the vector of independent variables, $X(t)$, consist not only of exchange rates and foreign competitors' prices, but also other macroeconomic and industry contingencies. Some variables may be continuous (e.g., macroeconomic variables or input, competitor, and substitute prices) while others may be expressed as indicator variables (e.g., technological state or political and government policy variables).

Changes in the estimated foreign exchange coefficients is not the only implication of the expanded multivariate model. A significant foreign exporter price coefficient may suggest very different hedging practices than would a model incorporating only the variables of primary interest in finance research--exchange rate, interest rate, or commodity prices. The exposures to foreign exchange and macroeconomic variables may require strategic risk management responses rather than hedging through the use of financial market instruments. The next section elaborates on some of the implications of the integrated approach to risk assessment and management.

\section{IMPLICATIONS OF MULTIVARIATE ASSESSMENT OF ECONOMIC EXPOSURES}

The multivariate approach to economic exposure has important implications for corporate risk assessment and hedging. These implications have generally been overlooked in previous research on economic exposure and corporate risk management.

A fundamental conclusion from the earlier discussion is that specifying a simple bivariate model of foreign exchange exposure can result in a very different assessment of corporate exposure than estimating a multicurrency exposure model. Using a series of bivariate models would be inappropriate given the failure of such an approach to take into consideration the correlations among exchange rates. 
Hedging practices based on simple bivariate exposure estimates will generally result in suboptimal risk management practices. Firms may engage in inadequate or excessive hedging to cover their currency exposures if they fail to take into consideration the correlations among various currencies. Significant exposure coefficients estimated in a series of bivariate models may be insignificant in a combined multivariate model. Conversely, insignificant coefficients from bivariate models may be significant in a multivariate model. The signs of significant relations may even be reversed in moving from a bivariate to a multivariate model. The implication of this latter observation is that firms engaging in hedging practices based on bivariate exposure estimates may actually exacerbate their aggregate exposure.

Furthermore, movements in foreign exchànge rates may be correlated with other environmental contingencies for which a corporation is interested in developing hedging strategies. Examples of such variables include interest rates, input prices, and the prices of competing, substitute, or complementary goods. Even political and social risks affecting businesses could have significant inverse relations with the value of a country's currency. Hence, foreign exchange exposure and political risk, two facets of corporate risk management generally treated in isolation from foreign exchange risk, may be best modeled in a single multivariate model to determine corporate exposure.

While the implications of including non-currency variables in a model of foreign exchange exposure are similar to the implications of moving from a single currency to a multiple currency model, the inclusion of these additional variables suggests very different corporate hedging practices. While financial market instruments exist for hedging currency, interest rate, and commodity price exposures, financial hedging instruments may not be available to hedge movements in many critical environmental contingencies such as the prices of non-commodity inputs or competitors' goods. Corporate responses to these risks may require strategic rather than financial hedging practices. For example, firms facing uncertainty regarding the price of a non-commodity input may seek to vertically integrate to control a key supplier. Exposure to competitors' prices may be reduced through a strategy of product differentiation increasing customer brand loyalty and switching costs. 
The integrated risk management perspective reflected in the multivariate estimation of exposure coefficients suggests a complementary role for financial and strategic hedging practices. Where appropriate financial instruments exist, they may be relatively inexpensive (i.e., low transaction cost) means to hedge short-term economic exposures. However, financial hedging instruments cover only a limited subset of the environmental contingencies affecting firm value and the time frame for corporate economic exposures frequently exceeds the terms for financial hedging instruments. Where appropriate financial hedging instruments do not exist, firms have available a variety of strategies to deal with economic exposures. These include gaining control over extemal contingencies, cooperating with suppliers, buyers, or competitors, and developing organizational flexibility. Increasing organizational flexibility can be viewed as the purchase of an real option (Kogut, 1983; Sanchez, 1993). Diversification into new product or geographic markets, and operational flexibility have option characteristics that can be used to hedge corporate exposures in a manner analogous to financial options.

An important distinction between financial and strategic hedging is that whereas financial hedging instruments can be tailored to specific financial market contingencies (e.g., particular foreign exchange rates, interest rates, or commodity prices), changes in strategies affect corporate risk exposures across a variety of variables. Hence, while financial instruments can be tailored to specific contingencies that have an impact on firm value, changes in strategy are likely to have broad implications across a corporation's set of exposure coefficients. This observation indicates that rather than a simple one-to-one mapping between exposures and relevant hedging instruments, prescribing hedging practices involving changes in strategy must take into consideration the entire risk exposure profile of a firm. As such, it may often be inadequate to make simplistic assertions about the appropriateness of strategic changes as responses to particular risk exposures.

Consider, for example, the case of a firm with a significant negative exposure to input prices. Such a firm may be encouraged to engage in backward vertical integration through developing an inhouse capacity to produce the inputs. Such a strategy would reduce the variability of input prices in local currency terms. At the same time, however, vertical integration could increase the firm's exposure to foreign exchange rate movements. This becomes evident if we consider a situation in which the local 
exchange rate appreciates making foreign inputs cheaper than the firm's own in-house inputs. Since the company continues to source inputs through its in-house production, the availability of lower cost imported inputs to competing firms would put the company at a competitive disadvantage.

This example illustrates the need for strategy research to move away from simplistic characterizations of changes in strategies as risk reducing or risk taking. Frequently, it is the case that while a change in strategy can be characterized as risk reducing with respect to a particular contingency, it increases exposures to other contingencies. Hence, there are trade-offs which must be explicitly considered in determining the role of strategic responses in corporate hedging.

If the proposed change in strategy involves acquiring an existing firm, estimates of the firm's own exposures and the acquisition candidate's exposures using a multivariate model could be compared to indicate the potential exposure coefficients associated with running the two firms as a single entity. The validity of such an assessment depends on whether management intends to significantly change the strategy of the acquired (or acquiring) unit after acquisition. For full hedging, the ideal candidate for a firm with exposure coefficients given by the vector, $\beta$, would be a firm of equivalent size with an exposure vector, $-\beta$. It is unlikely that such an ideal candidate would be found. Most acquisition candidates would have some exposure coefficients which are opposite in sign from those of the acquiring firm and other exposures with the same sign. Hence, acquisitions which reduce the firm's exposure along certain dimensions will increase the exposure to other environmental contingencies. While the "ideal" acquisition candidate is unlikely to exist, a linear combination of various acquisition candidates may approximate full hedging.

More realistically, furms will select acquisition candidates based on their strategic implications. Even when strategic rather than hedging considerations drive the selection of acquisition candidates, assessment of the risk implications may be an important input into the acquisition decision.

Unlike acquisitions or divestitures, the use of options has the potential to eliminate downside losses without eliminating the potential for upside gains. Currency options provide a good illustration of this property. If a firm is exposed to downside risk in the event of depreciation in the pound relative to the dollar, this downside risk can be averted through selling a pound put option or buying a dollar call option. 
Elimination of downside risk results from the option holder's flexibility to exercise the option or allow it to expire unexercised. To fully eliminate the downside economic risk, the exercise price must be equivalent to the current spot price. For such an "at the money--spot" option, the writer of the option bears the full downside risk and receives the option premium for this risk-bearing service.

While the payoffs associated with options traded on financial markets are generally described in terms of just one contingency variable (e.g., a single foreign exchange rate), it is possible to reconceptualize option payoffs in terms of multiple contingencies. In fact, such a multivariate conceptualization may be much more appropriate than the typical univariate perspective when we seek to describe the risk management implications of corporate strategies with option characteristics. An ideal multivariate call option for a firm with exposure coefficients given by the vector $\beta$ would have a payoff expressed as $\max \left\{0,-\mathrm{x}(\mathrm{t}) \boldsymbol{\beta}-\mathrm{P}_{\mathrm{e}}\right\}$, where $\mathrm{P}_{\mathrm{e}}$ is the exercise price reflecting the initial capital investment needed to implement the strategy. Such an option could be implemented through changes in strategies resulting in increased flexibility. Options traded on financial markets could be used in combination with changes in strategic flexibility to achieve management's desired option hedge. Hence, financial market instruments and strategic choices have complementary roles in hedging economic exposure.

\section{ESTIMATION OF ECONOMIC EXPOSURES}

Up to this point, we have considered theoretical arguments supporting multivariate modeling of economic exposure and the implications of this approach for corporate exposure assessment and hedging. We turn now to the practical issues involved in specifying and estimating multivariate models of corporate economic exposure. The discussion begins by looking at the choice of a dependent variable.

\section{Choosing the Dependent Variable and Specifying an Estimable Model}

One point of confusion in the existing discussions of economic exposure regards the choice of the dependent variable. This confusion is evident in statements such as: "Foreign exchange exposure can be defined as the sensitivity to shifts in exchange rates of either a firm's cash flows or its reported profits, or some subset thereof. While the cash flow perspective makes more economic sense, the reporting 
perspective also matters to the extent that it affects managerial decisions or financial market reactions" (Lessard, 1986: 166-167) and "Economic exposure is a measure of the reduction in cashflow and value that a business may experience as a result of a real adjustment in the foreign exchange rate" (Bishop \& Dixon, 1992: 329). Oxelheim and Wihlborg state, "Economic exposure would be defined correspondingly as the sensitivity of net present value, cash flows, or profits with respect to, for example, exchange rate changes....For example, some firms worry about fluctuations over time in market value, others about the magnitude of fluctuations in profits or cash flows" (1987a: 89). These statements raise the question whether cash flows or firm value are appropriate dependent variables when measuring economic exposure.

Shapiro $(1975 ; 1977)$ focused on cash flow sensitivity to nominal movements in foreign exchange rates. Later, Shapiro (1984) acknowledged that the emphasis on nominal cash flows in his earlier work was inappropriate and, following Cornell (1980) and Wihlborg (1980), asserted real cash flows as theoretically appropriate for measuring economic exposure. The need to use real cash flows, as opposed to nominal values, is, however, not explicit elsewhere in Shapiro's writings on measuring economic exposure (Garner \& Shapiro, 1984; Shapiro (1992).

While focusing on real cash flows is superior to looking simply at nominal cash flows, the emphasis on cash flows needs to be questioned. Looking at the magnitude of net cash flows is clearly incorrect when a firm's level of capitalization changes over time. Consider a firm that raises new capital through debt or equity financing or simply through retention of earnings. Investment of this capital in projects generating returns equal to the cost of capital does not increase shareholder value (Rappaport, 1986). Such investments do, however, increase net cash flows.

Even for firms with constant levels of capitalization, emphasizing real cash flow sensitivity overlooks the distortions in current cash flows. Short-term cash flows provide little information about the value created by a firm's strategy. For example, new strategic initiatives often require several years of negative cash flows before entering into a period of positive cash flows. These negative cash flows may result from intensive investment in $R \& D$, plants and equipment, and marketing, and limited initial sales. From a value creation perspective, we are actually interested in the sensitivity of a firm's net present value 
to exchange rate movements. NPV takes into consideration the discounted cash flows over the life of an investment. Since short term cash flows are not a direct measure of value creation, cash flows and firm value can present quite divergent criteria for estimating a firm's economic exposure. Unlike current cash flows, NPV is a direct measure of firm value.

Calculation of a firm's NPV is, however, problematic, given the high uncertainty surrounding forecasted cash flows and the need to make appropriate assumptions regarding the discount rate and time horizon for a firm's operations. On the other hand, if capital markets are not fooled by accounting numbers (i.e., capital markets are able to ascertain the underlying value of the firm's competitive position), market valuation of shareholder equity can be used to measure firm value. This suggests that the market value of a firm's equity can be used as the dependent variable in determining a firm's economic exposure.

Using the total market value of the firm is, however, problematic because shifts in the size of the firm over time may not reflect shareholder wealth creation. For example, dividend payments reduce firm value. Issuing new shares of stock increases the total market value of the firm but will only change the value of previously outstanding shares if the newly raised capital is invested in projects earning a rate of return which differs from the cost of capital. These observations indicate that using the total market value of equity as the dependent variable does not result in estimable exposure coefficients using time series data from a single firm if new shares are issued or dividends paid. For similar reasons, the use of total firm value precludes cross sectional comparison of exposure coefficients.

For estimation purposes, it is useful to specify firm value as a nonlinear function. For example, the relations previously expressed in equation (7) could be respecified as:

$$
V(t)=\beta_{0} S_{£}(t)^{\beta 1} S_{\Psi}(t)^{\beta 2} P(t) \beta 3_{\varepsilon}(t) .
$$

This equation can be rewritten in the log linear form:

$$
\log [\mathrm{V}(\mathrm{t})]=\log \left[\beta_{0}\right]+\beta_{1} \log \left[S_{\mathfrak{f}}(\mathrm{t})\right]+\beta_{2} \log \left[S_{\Psi}(t)\right]+\beta_{\mathrm{i}} \log [\mathrm{P}(\mathrm{t})]+\log [\varepsilon(t)]
$$

Taking the derivative of equation (10) with respect to $t$, we have:

$$
[d V(t) / d t] / V(t)=\beta_{1}\left[d S_{\mathfrak{f}}(t) / d t\right] / S_{\mathfrak{f}}(t)+\beta_{2}\left[d S_{\Psi}(t) / d t\right] / S_{\Psi}(t)+\beta_{i}[d P(t) / d t] / P(t)+\eta(t)
$$


where $\eta(t)=[d \varepsilon(t) / d t] / \varepsilon(t)$. The coefficients in this equation can be interpreted as the elasticities of firm value with respect to each of the independent variables (Glaister, 1978: 117-118). For example, $\beta_{1}$ measures the elasticity of firm value with respect to movements in the dollar spot price of the pound (conditional on all other variables in the model). This contrasts with estimation of the coefficients in equation (7) which, as discussed earlier regarding equation (1), can be interpreted as the dollar magnitudes of firm exposures.

Using discrete data, we can express the equation (11) relations in terms of the rates of change of each of the variables:

$$
R_{V}(t)=\beta_{1} R_{\mathcal{L}}(t)+\beta_{2} R_{\Psi}(t)+\beta_{3} R_{P}(t)+\eta(t)
$$

Treating $R_{V}(t)$ as the rate of return to shareholders for a specific firm, this equation provides a basis for estimating exposure coefficients using time series data. Unlike models of economic exposure using cash flows, NPV, or market value of equity as the dependent variable, expressing the dependent variable as the rate of return to shareholders results in a model which is invariant to changes in the size of the firm over time. Estimated parameters from equation (12) are also comparable across organizations. ${ }^{2}$

\section{Deviations from Expectations or Total Variability?}

Equation (12) presented an estimable multivariate model of corporate economic exposure. As specified, changes in shareholder returns are a function of changes in a set of independent variables. Hence, this specification measures economic exposure with respect to total movements in the independent variables rather than focusing solely on movements that are deviations from expectations. Since other researchers have argued for specifying economic exposure only in terms of deviations from expectations, it is worthwhile to briefly considering whether deviations from expectations or total variability is most appropriate.

Adler and Dumas (1984) argued economic exposure to foreign exchange rates should be defined in terms of random deviations from expected real rates. Oxelheim and Wihlborg state, "There are reasons to distinguish between exposure to anticipated and unanticipated changes in, for example, the exchange rate. The firm can incorporate the former in its budget and planning process, while exposure to 
unanticipated changes constitutes the firm's risk exposure"(1987a: 88). Emphasizing unanticipated currency movements accommodates hedging using available financial instruments. The primary financial hedging tools (futures and forward contracts, options, and swaps) allow firms to hedge unexpected deviations from the market's expected price but do not hedge total price variability. Financial hedging instruments do not, therefore, eliminate exposure to widely expected price changes.

Despite the arguments for specification of exposure models in terms of deviations from expectations, most empirical models purporting to measure economic exposure as a regression coefficient do not incorporate expectations (e.g., Garner \& Shapiro, 1984; Jorion 1990; Oxelheim \& Wihlborg, 1987b; Rawls \& Smithson, 1990; Shapiro, 1992: 242-243). Presumably, forward market prices could be incorporated into such models but, in order to simplify their models, these researchers have chosen not to incorporate available market expectations proxies. If however, variables were included in the economic exposure model for which there are no existing forward markets to generate proxies for expected future prices (e.g., the price of non-commodity competitors' goods), the lack of data would present a significant obstacle to exposure model estimation.

Beyond the pragmatic concern of data availability, there are also theoretical arguments for using the total variability of the independent variables rather than just deviations from expectations. From a top management perspective, exposure to both predictable and unpredictable changes are important. Downside potential rather than unpredictability is the essence of risk for strategic decision makers (Aaker and Jacobson, 1990). Consider for example, the emergence of a substitute technology. While information about the emerging technology may be widely known, firms unable to appropriate the technology stand to lose sales, or at the extreme, be completely displaced by competitors and new entrants with the resources necessary to exploit the technology. Hence, while the technological change is predictable, it constitutes a threat, and hence a risk, for the incumbent firm.

Since managers are interested in how the variability of environmental contingencies affects corporate performance regardless of whether the variability is foreseen or not, it makes sense to specify models of economic exposure in terms of total variability of the independent variables. While defining economic exposure just in terms of unanticipated movements in the independent variables accommodates 
the properties of financial market hedging instruments, such a definition is inconsistent with managers' concerns about the impact of both foreseeable and unforseeable contingencies.

\section{Selection of Regressors}

Another important issue in specifying a model of corporate economic exposure is the selection of regressors. In order to empirically estimate multivariate exposure models, we need a theoretical grounding for the selection of regressors. Furthemore, we need to deal with the potential problem of multicollinearity among the chosen regressors.

The environmental contingencies relevant to explaining corporate returns to shareholders vary across industries and firms within industries. The explanatory power of any single model is likely to vary considerably across industries and firms. Hence, it would be unreasonable to postulate a single set of regressors applicable to all firms. Instead, our objective ought to be to glean from existing theory a typology of potentially relevant environmental contingencies. Some such contingencies may prove significant across a wide range of firms, while others may not be significant. The significance of particular environmental variables across different industries and firm strategies within industries remains as an interesting empirical issue for future research.

Previous theoretical treatments of corporate risk have done little to develop a comprehensive typology of relevant environmental contingencies. Given the emphasis on particular environmental contingencies in most of the previous risk management research, it is necessary to draw on a broad range of literature to formulate a more comprehensive view of corporations' risk profiles.

The typology of uncertain environmental contingencies offered by Miller (1992) sought to respond to the need for an integrated framework for corporate risk assessment. The typology categorized environmental uncertainties into two broad categories: (1) general environmental and (2) industry. General environmental uncertainties include political, government policy, macroeconomic, social, and natural contingencies. Industry dynamics involve input market, product market, and competitive uncertainties. While these factors have generally been analyzed as industry characteristics (e.g., Porter, 1980), it should be noted that firms' exposures to each of the industry uncertainties may differ 
significantly depending on the unique characteristics of firms' strategies. The Miller (1992) typology provides a starting point from which to develop empirical proxies for the contingencies relevant to corporate risk assessment.

Using theory to select a broad set of regressors to include in a model of corporate risk exposure, we are likely to encounter multicollinearity. Correlations among the regressors may be spurious or involve causal relations. For example, currency values may be pegged to one another. Comovements in interest rates and currency values may reflect causal relations or be due to other macroeconomic variables. The earlier example of pricing exports in the home currency rather than the export market currency (and hence gaining market share when the home currency devalues) illustrated that even competitive variables may be correlated with currency values. Hence, in order to empirically estimate a multivariate model of economic exposure, we must assess and deal with multicollinearity.

In a multivariate model, each coefficient estimate takes into account not only the correlation between a particular exogenous variable and the endogenous variable, but also the correlations between the variable and each of the other exogenous variables and the correlations of the other exogenous variables with the endogenous variable. This was shown earlier for the case of a simple two currency model of exchange exposure (equations 5 and 6). OLS estimates use only the variation unique to a particular regressor. That is, the common variation among the exogenous variables is partialed out in estimating the regression coefficients. The higher the correlations among the exogenous variables, the less unique variability associated with any given exogenous variable. Hence, there is less information to calculate the coefficients.

As the exogenous variables become more highly correlated, the standard errors of the regression coefficients increase. Thus, while estimated OLS coefficients remain unbiased, they are imprecise and likely to be insignificant. Yet, while individual exposure coefficients may not be significant, the aggregate exposure (reflected in the regression F) may be significant. The implication is that a firm may have a significant economic exposure to the model variables but the individual coefficients in the multivariate model provide no guidance as to how to hedge this exposure. 
What are some possible approaches for dealing with this problem? One approach is to simply drop one or more variables from the multivariate equation. Because of the resulting misspecification, this approach causes the estimated coefficients of the remaining variables to be biased. A second alternative is to use principal components analysis to generate a set of orthogonal composite variables. In order to be managerially relevant, the principal components must be interpretable. A third approach is to shrink the OLS coefficient estimates by using ridge or Stein estimation. Ridge and Stein estimation present the drawback that the resulting estimators have unknown distributions so that hypothesis testing cannot be undertaken (Kennedy, 1985).

As noted, the approaches to dealing with multicollinearity involve trade-offs. Simple bivariate models of exposure coefficients go to the extreme of eliminating collinearity but result in biased parameter estimates due to model misspecification. In shifting to a multivariate model, problems with misspecification are reduced but multicollinearity becomes an issue. Hence, multivariate modeling of exposure involves trading off misspecification for multicollinearity. Existing econometric research provides guidelines for making such tradeoffs (e.g., Belsley, Kuh, \& Welsch, 1980).

\section{Temporal Instability of Exposure Coefficients}

Finance researchers have cautioned that corporate economic exposures may be unstable over time (Adler \& Dumas, 1984; Garner \& Shapiro, 1984; Shapiro, 1992). Oxelheim and Wihlborg (1987b: 115) stress coefficient stability using time-series estimation depends on the government policy regime, including both domestic and foreign fiscal and monetary policies.

While instability of exposure coefficients over time is viewed as problematic by finance researchers, temporal instability is of fundamental interest in the field of strategy. Largely overlooked in finance discussions of economic exposure is the observation that changes in corporate strategy give rise to changes in economic exposure. Corporate changes in strategy and hedging policies may be much more influential in shifting economic exposure coefficients than changes in the govemment policy regime. If so, the period for time series estimation of corporate economic exposure should be limited to the duration of the corporate strategy. As noted earlier, shifts in strategy such as acquisitions, divestitures, or changes 
in strategic flexibility (i.e., strategies with option characteristics) will influence corporate exposure coefficients.

\section{RESEARCH DIRECTIONS}

In the past, strategy research has sought to measure risk as a single corporate or business level construct reflecting financial performance variability. The emphasis on risk measures such as the variance of accounting returns, stock returns beta and unsystematic risk, and the variance of analysts' earnings forecasts reflect the orientation toward general measures of firm risk (Miller \& Bromiley, 1990). The primary applications of such measures in strategy research have been studies on corporate risk-return relations, and the risk implications of specific strategies (corporate diversification being the research domain most widely incorporating risk measures). In focusing on general measures of risk, this research has not addressed the managerial concern for determining exposures to specific environmental

contingencies and developing appropriate hedges for specific exposures. Nor does it take into consideration the possibility that changes in strategy may have little impact on the overall risk of the firm despite changing significantly the exposures to particular environmental contingencies. By dealing at the level of general measures of risk, strategy research offers only vague hypotheses regarding how strategy affects risk and vice versa.

The integrated risk management perspective developed in this paper offers an alternative approach to that of earlier strategy research. Multivariate modeling of economic exposure offers the possibility of assessing corporate exposures along many different dimensions. Distinguishing among exposures is likely to be quite important for explaining firm strategic responses. Specification of appropriate strategies for hedging economic exposures depends on assessment of the full profile of risk exposures. Casual observation suggests companies respond quite differently to exposures to political and government policy, macroeconomic, input and product market, and competitive factors that impact firm value. Breaking the risk construct into distinct exposures to multiple environmental contingencies allows for more precise specification of the relations between risk and strategy. The development and testing of 
such hypotheses could provide valuable guidelines for corporate strategic risk management and suggest appropriate (complementary) roles for financial and strategic hedging practices.

The instability of corporate exposure coefficients over time offers an interesting research opportunity. We know of no previous research looking at the shifts in exposure coefficients following changes in corporate strategies.

Application of option theory to strategy research is just beginning (see Bowman \& Hurry, 1993; Sanchez, 1993). Viewing strategic moves resulting in increased flexibility as options provides a useful conceptualization for thinking about strategic flexibility as a means to hedge corporate downside risk. Option theory provides a conceptual framework for thinking about how specific strategies may be used in response to specific corporate risk exposures. However, since strategic decisions influence corporate exposures to a broad set of environmental contingencies, strategy research cannot assume the simple oneto-one mapping between exposures and hedging instruments generally followed in finance research. Rather, firms face a complex set of interrelated exposures and altering corporate strategies is likely to affect many, if not all, exposures. Hence, changes in strategies resulting in increased flexibility can be viewed as the purchase of options with payoffs contingent on multiple environmental contingencies. 


\section{ENDNOTES}

${ }^{1}$ As is typical, the path diagram assumes all variables, except the error term, are standardized. This eliminates the need to explicitly model the intercept in the path diagram.

${ }^{2}$ The more general form of equation (7) for a model of economic exposure using $\mathbf{n}$ independent variables would be:

$V(t)=\prod^{n} \beta_{0} x_{i}(t) \beta i_{\varepsilon(t) .}$

$\mathrm{i}=1$

This gives rise to the estimable rate of return model:

$R_{V}=\sum_{i=1}^{n} \beta_{i} R_{i}(t)+\eta(t)$

where $R_{V}$ is rate of return to shareholders and $R_{i}$ is the rate of change of $X_{i}$. 


\section{REFERENCES}

Aaker, D. A. \& Jacobson, R. 1990. The risk of marketing: The roles of systematic, uncontrollable and controllable unsystematic, and downside risk. In Bettis, R. A. and Thomas, H. (Eds.), Risk. strategy, and management: 137-160. Greenwich, Connecticut: JAI Press.

Adler, M. \& Dumas, B. 1984. Exposure to currency risk: Definition and measurement. Financial Management, 13 (2): 41-50.

Batten, J., Mellor, R. \& Wan, V. 1993. Foreign exchange risk management practices and products used by Australian firms. Journal of International Business Studies, 23: 557-573.

Belsley, D. A., Kuh, E., \& Welsch, R. E. 1980. Regression diagnostics: Identifying influential data and sources of collinearity. New York: John Wiley.

Bishop, P. \& Dixon, D. 1992. Foreign exchange handbook. New York: McGraw-Hill.

Bowman, E. H. \& Hurry, D. 1993. Strategy through the option lens: An integrated view of resource investments and the incremental-choice process. Academy of Management Review, 18: 760-782.

Cornell, B. 1980. Inflation, relative price changes, and exchange risk. Financial Management, 9 (3): 3034.

Dufey, G. 1972. Corporate finance and exchange rate variations. Financial Management, 1 (2): 51-57.

Garner, C. K. \& Shapiro, A. C. 1984. A practical method of assessing foreign exchange risk. Midland Corporate Finance Journal, 2 (3): 6-17.

Glaister, S. 1978. Mathematical methods for economists (revised ed.). Oxford, England: Basil Blackwell.

Grammatikos, T., Saunders, A. \& Swary, I. 1986. Returns and risks of U.S. bank foreign currency activities. Journal of Finance, 41: 761-682.

Jorion, P. 1990. The exchange rate exposure of U.S. multinationals. Journal of Business, 63: 331-345.

Kawai, M. \& Zilcha, I. 1986. International trade with forward-futures markets under exchange rate and price uncertainty. Journal of International Economics, 20: 83-98.

Kennedy, P. 1985. A guide to econometrics (2nd ed.). Cambridge, Massachusetts: MIT Press.

Kenny, D. A. 1979. Correlation and causality. New York: John Wiley.

Kogut, B. 1983. Foreign direct investment as a sequential process. In Kindleberger, C. P. \& Audretsch, D. B. (Eds.) The multinational corporation in the 1980s: 38-56. Cambridge, Massachusetts: MIT Press.

Kohn, K. 1990. Are you ready for economic-risk management? Institutional Investor, 24 (11): 203-207.

Lessard, D. R. 1986. Finance and global competition: Exploiting financial scope and coping with volatile exchange rates. In Porter, M. E. (Ed.) Competition in Global Industries: 147-184. Boston: Harvard Business School Press.

Lewent, J. C. \& Kearney, J. A. 1990. Identifying, measuring, and hedging currency risk at Merck. Continental Bank Joumal of Applied Corporate Finance, 2 (4): 19-28. 
Miller, K. D. 1992. A framework for integrated risk management in international business. Joumal of International Business Studies, 23: 311-331.

Miller, K. D. \& Bromiley, P. 1990. Strategic risk and corporate performance: An analysis of alternative risk measures. Academy of Management Journal, 33: 756-779.

Oxelheim, L. \& Wihlborg, C. 1987a. Exchange rate-related exposures in a macroeconomic perspective. In S. J. Khoury \& A. Ghosh (Eds.) Recent developments in international banking and finance, vol. 1: 87102. Lexington, Massachusetts: Lexington Books.

Oxelheim, L. \& Wihlborg, C. 1987b. Macroeconomic uncertainty: International risks and opportunities for the corporation. New York: John Wiley.

Porter, M. E. 1980. Competitive strategy. New York: Free Press.

Rappaport, A. 1986. Creating shareholder value. New York: Free Press.

Rawls, S. W. \& Smithson, C. W. 1990. Strategic risk management. Journal of Applied Corporate Finance, 2 (4): 6-18.

Sanchez, R. 1993. Strategic flexibility, firm organization, and managerial work in dynamic markets: A strategic-options perspective. In (Ed?) Advances in strategic management, Vol. 9: 251-291. Greenwich, Connecticut: JAI Press.

Shapiro, A. C. 1975. Exchange rate changes, inflation, and the value of the multinational corporation. Journal of Finance, 30: 485-502.

Shapiro, A. C. 1977. Defining exchange risk. Joumal of Business, 50: 37-39.

Shapiro, A. C. 1984. Currency risk and relative price risk. Joumal of Financial and Quantitative Analysis, 19: 365-373.

Shapiro, A. C. 1992. Multinational financial management (4th ed.). Boston: Allyn and Bacon.

Wihlborg, C. 1980. Economics of exposure management of foreign subsidiaries of multinational corporations. Journal of International Business Studies, 11 (3): 9-18. 
FIGURE 1

Path Diagram for Two Exchange Rates and Firm Value

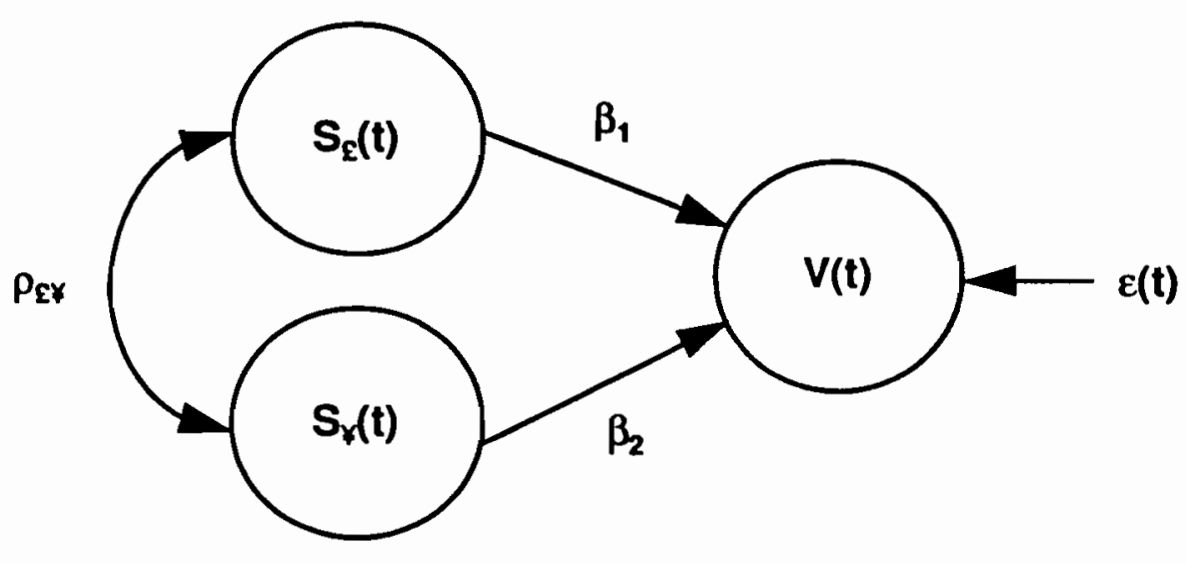




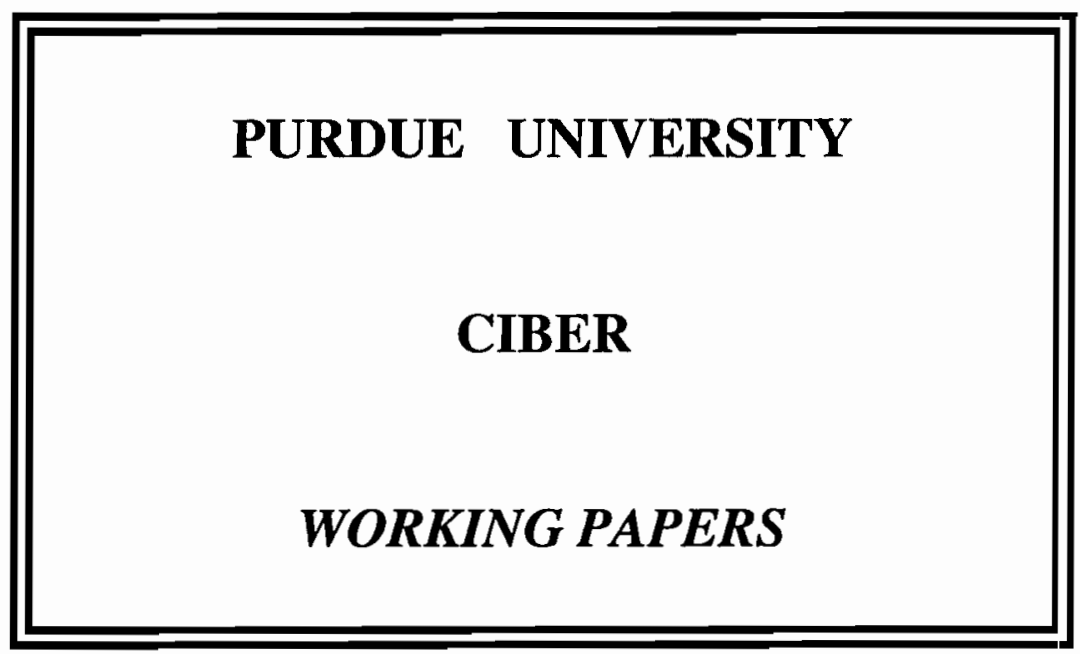


No. 93-101 Gordon M. Phillips, Robert J. Weiner -

"Information and Normal Backwardation as Determinants of Trading Performance: Evidence from the North-Sea Oil Forward Market." 1994. The Economic Journal.

No. 93-102 Stephen R. Goldberg, Frank L. Heflin

"The Association Between the Level of International Diversification and Risk"

No. 93-103 John A. Carison

"Risk Aversion, Foreign Exchange Speculation and Gambler's Ruin"

No. 93-104 John A. Cartson, Aasim M. Husain, Jeffrey A. Zimmerman

"Penalties and Exclusion in the Rescheduling and Forgiveness of Intermational Loans"

No. 93-105 Kent D. Miller

"Industry and Country Effects on Manager's Perceptions of Environmental Uncertainties." 1993. Joumal of International Business Studies, 24: 693-714.

No. 93-106 Stephen R. Goldberg and Joseph H. Godwin

"Foreign Currency Translation Under Two Cases-Integrated and Isolated Economies"

No. 93-107 Kent D. Miller

"A Comparison of Managers' Uncertainty Perceptions and Country Risk Indices"

No. 93-108 Jon D. Haveman

"The Effect of Trade Induced Displacement on Unemployment and Wages"

No. 93-109 Jon D. Haveman

"Some Welfare Effects of Dynamic Customs Union Formation"

No. 93-110 John A. Carison, Insook Kim

"Central Banks' Expected Profits From Intervention

If you would like to request copies of specific papers, please contact the Center for International Business Education and Research, Purdue University, Erannert School of Management, West Lafayette, IN 47907.

(Phone: 317/494-4463 or FAX: 317/494-9658) 
No. 94-001 Casper G. De Vries, Phillip A. Stork, Kees G. Koedijk

"Between Realignments and Intervention: The Belgian Franc in the European Monetary System"

No. 94-002 Casper G. de Vries, K. U. Leuven

"Stylized Facts of Nominal Exchange Rate Returns"

No. 94-003 Kent D. Miller

"Operational Flexibility Responses to Environmental Uncertainties"

No. 94-004 Kent D. Miller

"Economic Exposure and Integrated Risk Management"

No. 94-005 Kent D. Miller

"Diversification Responses to Environmental Uncertainties"

No. 94-006 John M. Hannon, Ing-Chung Huang, Bih-Shiaw Jaw

"International Human Resource Strategy and Its Determinants: The Case of Multinationals and Their Subsidiaries in Taiwan"

No. 94-007 John M. Hannon, Ing-Chung Huang, Bih-Shiaw Jaw

"International Human Resource Strategy andControl: The Case of Multinationais and Their

Subsidiaries"

No. 94-008 John M. Hannon, Yoko Sano

"Customer-Driven Human Resource Policies and Practices in Japan"

No. 94-009 John A. Carison, Insook Kim

"Leaning Against the Wind: Do Central Banks Necessarily Lose?"

No. 94-010 John A. Carlson, David W. Schodt

"Beyond the Lecture: Case Teaching and the Learning of Economic Theory"

No. 94-011 Alok R. Chaturvedi, Hemant K. Jain, Derek L. Nazareth

"Key Information Systems Maragement Issues in Developing Countries: Differences in the Indian and US Contexts"

If you would like to request copies of specific papers, please contact the Center for International Business Education and Research, Purdue University, Krannert School of Management, West Lafayette, IN 47907.

(Phone: $317 / 4944463$ or FAX: 317/494-9658) 